\title{
Structure and function of the cystic fibrosis transmembrane conductance regulator
}

M.M. Morales, M.A.M. Capella and A.G. Lopes
Laboratório de Fisiologia Renal, Instituto de Biofísica Carlos Chagas Filho, Universidade Federal do Rio de Janeiro, Rio de Janeiro, RJ, Brasil

\section{Correspondence \\ M.M. Morales \\ Instituto de Biofísica Carlos \\ Chagas Filho, UFRJ, CCS, Bloco G \\ 21949-900 Rio de Janeiro, RJ \\ Brasil \\ Fax: + 55-21-280-8193 \\ E-mail: mmorales@ biof.ufrj.br}

The author received the "Young

Talent in Life-Sciences-98" award for this article from the Sociedade Brasileira de Bioquímica e Biologia

Molecular and Amersham Pharmacia Biotech.

Research supported by PADCT, CN Pq and FUJB.

Received March 3, 1999

Accepted March 15, 1999

\begin{abstract}
Cystic fibrosis (CF) is a lethal autosomal recessive genetic disease caused by mutations in the $\mathrm{CF}$ transmembrane conductance regulator (CFTR). Mutations in the CFTR gene may result in a defective processing of its protein and alter the function and regulation of this channel. Mutations are associated with different symptoms, including pancreatic insufficiency, bile duct obstruction, infertility in males, high sweat $\mathrm{Cl}^{-}$, intestinal obstruction, nasal polyp formation, chronic sinusitis, mucus dehydration, and chronic Pseudomonas aeruginosa and Staphylococcus aureus lung infection, responsible for $90 \%$ of the mortality of CF patients. The gene responsible for the cellular defect in CF was cloned in 1989 and its protein product CFTR is activated by an increase of intracellular cAMP. The CFTR contains two membrane domains, each with six transmembrane domain segments, two nucleotide-binding domains (NBDs), and a cytoplasmic domain. In this review we discuss the studies that have correlated the role of each CFTR domain in the protein function as a chloride channel and as a regulator of the outwardly rectifying $\mathrm{Cl}^{-}$channels (ORCCs).
\end{abstract}

Key words

- CFTR

- Cystic fibrosis

- Chloride channel

- Function

- Structure

- Mutations

\section{Introduction}

Cystic fibrosis (CF) is a lethal autosomal recessive disorder in which abnormal regulation of epithelial $\mathrm{Cl}^{-}$channels is associated with the pathophysiology of the disease $(1,2)$. The hallmarks of CF include thick and dehydrated airway mucus, pancreatic insufficiency, bile duct obstruction, infertility in males, reduced fertility in females, high sweat $\mathrm{Cl}^{-}$, intestinal obstruction, nasal polyp formation, and chronic sinusitis (3). The major causes of morbidity and mortality in CF patients are opportunistic chronic lung infections caused by Pseudomonas aeruginosa and Staphylococcus aureus. These infections progressively destroy the lung parenchyma and lead to additional complications such as pulmonary hypertension, bronchiectasis, and right ventricular hypertrophy that ultimately lead to cardiorespiratory failure and death (4).

The cloning and subsequent studies of the CF gene have shown that its product is a low conductance, c-AMP-regulated chloride channel with properties distinct from those of other $\mathrm{Cl}^{-}$channels expressed in epithelial cell membranes $(1,5,6)$. The protein presents significant homology with the ATP-binding cassette family of transporters, responsible for the transit of hydrophobic drugs and small peptides, which includes the multidrug resis- 
tance protein (7). Taken together, these characteristics support the hypothesis that this protein transports a substance that regulates other conductances, motivating its name, cystic fibrosis transmembrane regulator, or CFTR.

CFTR mRNA is expressed in the lung and other tissues, such as testis, duodenum, trachea and kidney (8) and was recently shown to be expressed in the human hypothalamus (9). The CFTR protein has a molecular weight of $180 \mathrm{kDa}$ and is usually localized on apical cell membranes but there is evidence that it is also expressed in the basolateral membrane of sweat duct epithelia $(10,11)$.

Morales et al. (12) have shown that the CFTR mRNA is expressed in human kidney cortex and medulla. In the rat, it is expressed along all nephron segments except glomerulus. It is hypothesized that CFTR participates in $\mathrm{Cl}^{-}$reabsorption in these epithelia, but its role in renal function is not well understood since renal dysfunction is not observed in patients with cystic fibrosis.

Mutations in the CFTR gene reduce $\mathrm{Cl}^{-}$ permeability in several affected exocrine epithelial cells. This defect has attracted attention to the chloride transport function of CFTR and to the other $\mathrm{Cl}^{-}$channels that may

Figure 1 - Illustration of the predicted two-dimensional or secondary structure of the CFTR protein. The CFTR domains are shown. TMD1 and TMD2: transmembrane-spanning domains 1 and 2, respectively; $R$ domain: regulatory domain; NBD1 and NBD2: nucleotide-binding domains 1 and 2, respectively. A summary of the selected and important mutations in NBD1 and NBD2 discussed in this review is also shown. Modified from Ref. 14.

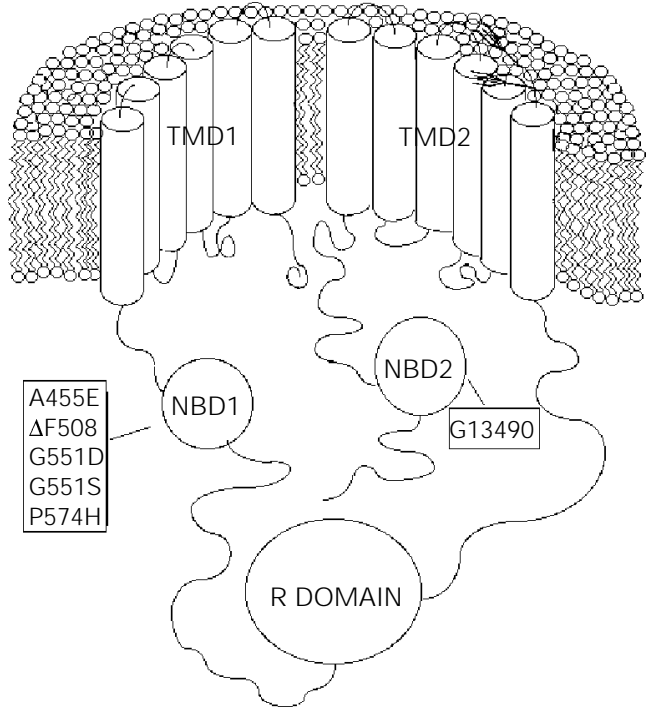

serve as redundant pathways for $\mathrm{Cl}^{-}$secretion across the apical membrane in response to cAMP or other stimuli. The importance of each CFTR domain in the chloride channel and conductance regulator functions of the protein as well as the influence of the most common mutations in $\mathrm{CF}$ will be discussed in this review.

\section{The CFTR structure}

The CF gene has been localized in human chromosome 7 and an analysis of the cDNA sequence has shown that the gene product, the CFTR protein, consists of 1,480 amino acids (13). Based on the hydropathy analysis of the amino acid sequence of CFTR, Collins et al. (14) proposed a putative model schematically illustrated in Figure 1. Beginning at the $\mathrm{N}$ terminus, the protein has six transmembrane-spanning domains followed by a first nucleotide-binding domain (NBD) with Walker A and B consensus sequences that bind ATP. Flanking this site, a large regulatory domain rich in cAMP-dependent kinase and protein kinase $\mathrm{C}$ phosphorylation sites is followed by a second set of six transmembrane-spanning domains and a second NBD that binds ATP. Morales et al. (12) described the existence of a functional alternative form of CFTR in rat trachea, lung and kidney. This alternative structure contains only the first transmembrane domain (TMD1), the first NBD and the regulatory domain (RD) and is designated TNR-CFTR. In the kidney, the TNR-CFTR is expressed in a tissuespecific manner primarily in the renal medulla and conserves the functional characteristics of the wild-type CFTR. This CFTR form is also found in human kidney medulla, but not in human kidney cortex.

The functional significance of this variant remains to be elucidated, but Morales et al. (12) raised two hypotheses: since several related members of the ATP-binding cassette family to which the CFTR belongs function in intracellular organelles as half 
molecules with the TMD1-NBD1 motif(1517), there is a possibility that TNR-CFTR may have a basic function in intracellular organelles rather than in plasma membrane. Another possibility is based on the fact that this unusual form of mRNA processing occurs only in the renal medulla, a portion of the kidney with high osmolality. This tissuespecific processing of CFTR mRNA may create functional isoforms that can protect the kidney from functional defects in CF.

\section{Secretory chloride channel function of CFTR}

Several laboratories using different techniques have definitely shown that the CFTR functions as a low conductance (7-12 pS), cAMP-regulated $\mathrm{Cl}^{-}$channel $(6,18-20)$. This conductance is independent of the voltage and the time the voltage is applied to the membrane (18). The CFTR $\mathrm{Cl}^{-}$channel is insensitive to the $\mathrm{Cl}^{-}$channel-blocking drug, 4,4'-diisothiocyanostilbene-2,2'-disulfonic acid, but can be inhibited at least in part by other blocking agents such as diphenylamine2-carboxylic acid, 5-nitro-2-[3-phenylpropylamino]-benzoic acid, and glybenclamide $(18,21)$.

Phosphorylation by cAMP-dependent protein kinase (PKA) and ATP hydrolysis or binding are necessary for the channel to become active and remain so $(19,20,22,23)$. Phosphorylation of the channel seems to occur only in the RD of the channel, whereas ATP binding or hydrolysis occurs in one or both of the NBD.

It is believed that the first transmembrane domain (TMD1) plays a role in the formation of the channel pore. The removal of a large portion of TMD1 including segments M1-M4 (M representing an individual membrane-spanning domain) reduces the single channel conductance of CFTR by $30 \%$, without affecting ion selectivity, demonstrating that internal sites can function as translation initiation codons (24). These results agree with those of Oblatt-Montal et al. (25) who showed that peptides with sequences corresponding to M1, M3, M4 and M5 do not form channels, whereas hetero-oligomers of M2 and M6 exhibit channel characteristics that emulate wild-type CFTR. McDonough et al. (26) hypothesized that both M6 and M12 interact to form the pore structure of CFTR. These studies suggest that spliced forms of CFTR could contribute significantly to overall $\mathrm{Cl}^{-}$secretion in vivo.

\section{CFTR is also a conductance regulator}

The original hypothesis that CFTR would function as a conductance regulator seems to be correct, as several ion transport abnormalities found in cystic fibrosis airway epithelial cells cannot be explained by mutations in the CFTR chloride channel.

Schwiebert et al. (27) showed that CFTR regulates outwardly rectifying $\mathrm{Cl}^{-}$channels (ORCCs) by an autocrine mechanism involving ATP release and other researchers suggested that the CFTR is a dual ATP and chloride channel $(28,29)$. However, several researchers were unable to detect ATP release by CFTR-expressing cells (30-33). These contradictory results suggest that there is some not yet understood relationship between the CFTR and ATP.

Devidas and Guggino (34) recently proposed three possible models for the release and function of ATP (Figure 2): 1) ATP, as well as $\mathrm{Cl}^{-}$, may pass through the CFTR itself; 2) ATP may pass through a channel that is different from the CFTR, but is regulated by it; 3) ATP-loaded vesicles fuse at the membrane level with the CFTR, followed by an exocytotic release of ATP via a $\mathrm{Cl}^{-}$osmotic gradient mediated through the CFTR.

Once out of the cell, ATP may interact with purinergic receptors that, once activated, may stimulate ORCCs through second messenger pathways, increasing chloride transport across the cell. 
Figure 2 - Membrane model depicting the role of ATP release in the interaction between the cystic fibrosis transmembrane conductance regulator (CFTR) and other conductances. In the polarized cells of airway epithelia the chloride exit occurs through the CFTR. A, ATP and $\mathrm{Cl}^{-}$are transported by the CFTR. ATP may interact and activate the purinergic receptor $\mathrm{P}_{2 \mathrm{y} 2}$ to stimulate the chloride transport via outwardly rectifying $\mathrm{Cl}^{-}$channels (ORCC) and block the reabsorption of $\mathrm{Na}^{+}$through the epithelium sodium channel $(\mathrm{ENaC})$. $B$, ATP is released from the cell via an ATP transporter regulated by the CFTR. Once in the extracellular compartment ATP stimulates ORCC and inhibits the $\mathrm{ENaC}$ via purinergic receptors. $\mathrm{C}$, The ATP located in intracellular vesicles fuses with the membrane containing the CFTR and the transport of ATP through CFTR occurs secondary to the osmotic chloride gradient. The ATP in the extracellular compartment stimulates the purinergic receptor to activate ORCC and inhibits the $\mathrm{ENaC}$ through intracellular second messengers. Modified from Ref. 34

Xenopus oocytes lack ORCCs that interact with CFTR, which makes them an ideal model system to study CFTR functions. Recently, Schwiebert et al. (35) constructed varied mutant forms of CFTR and transfected them to Xenopus oocytes and in IB31 cells, a CF bronchial epithelial cell line extensively used to study CFTR function, in order to investigate the $\mathrm{Cl}^{-}$channel and ORCC regulatory functions of CFTR. They showed that the first TMD of CFTR is an essential part of the $\mathrm{Cl}^{-}$channel pore, necessary for proper $\mathrm{Cl}^{-}$conduction by CFTR and its selectivity. Conversely, the first NBD and the regulatory domain are essential for the ability of CFTR to regulate ORCCs. Thus, the roles of CFTR as a $\mathrm{Cl}^{-}$channel and a conductance regulator are not mutually exclusive, since one function can be eliminated

A

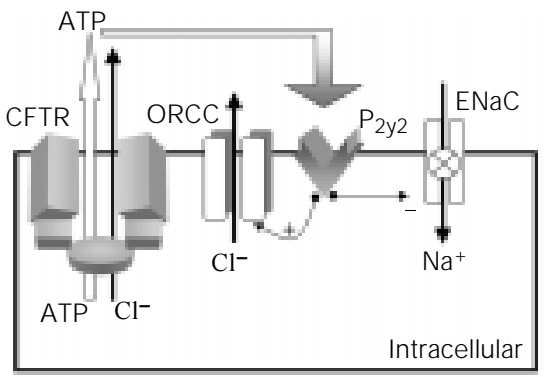

B

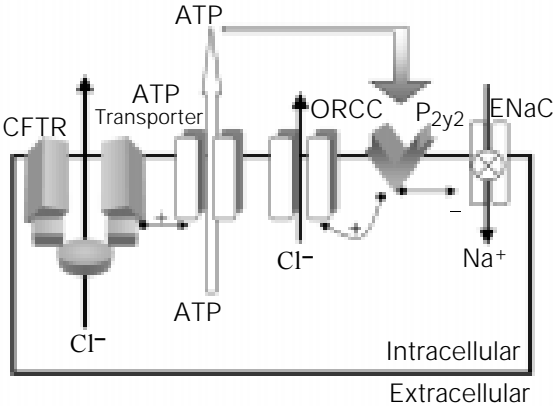

C

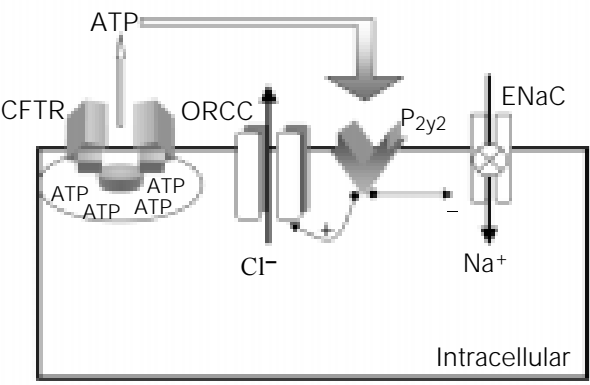

Extracellular while the other is preserved. In agreement with these results, Sugita et al. (36) showed that expression of CFTR in MDCK cells results in the appearance of a novel ATP channel with different properties from CFTR. However, deletion of the CFTR regulatory domain leaves the CFTR chloride channel pore intact, while eliminating the ATP channel. They also demonstrated that phosphorylation and nucleotide-hydrolysis-dependent gating of CFTR is directly involved in gating of the associated ATP channel, suggesting that the structural changes in CFTR that control its opening and closing mechanisms have similar effects on the ATP conduction pathway.

The fact that different domains of CFTR are responsible for its $\mathrm{Cl}^{-}$channel and ORCC regulatory functions led to an improved understanding of cystic fibrosis physiopathology. The mutations expected to cause the most severe disease are those that affect the ability of CFTR to function both as a chloride channel and as a conductance regulator. Mutations that retain at least one function or only partially reduce both functions may result in less severe pulmonary disease (37). In agreement with this assumption, Fulmer et al. (38), studying two CFTR mutations that lead to different phenotypic effects in CF patients, found that a CFTR mutation that preserves the $\mathrm{Cl}^{-}$channel and ORCC regulator functions also produced less severe pulmonary disease.

\section{Other functions of CFTR}

Epithelial $\mathrm{Na}^{+}$channels (ENaCs) are inhibited during activation of $\mathrm{Cl}^{-}$secretion in cells expressing CFTR $(39,40)$, suggesting that when CFTR is activated by cAMP, it inhibits ENaCs. The results of three recent studies suggest that CFTR and ENaCs may interact directly by protein-protein binding (41-43). Moreover, it has been shown that $\mathrm{Cl}^{-}$transport by CFTR contributes to the inhibition of ENaCs, but the mechanism is still unclear (44). 
Besides playing a role in $\mathrm{Cl}^{-}, \mathrm{ATP}$ and $\mathrm{Na}^{+}$transport, CFTR also leads to a multidrug resistance phenotype due to the extrusion of some therapeutic drugs $(45,46)$. Moreover, it seems that CFTR and P-glycoprotein, another protein of the ATP-binding cassette family, have complementary patterns of expression (47-49). The significance of these findings is still unclear.

\section{Mutations in the CFTR gene and its consequences}

In patients with $\mathrm{CF}$, more than 170 different mutations have been described in the CFTR gene (3). Affected individuals have two abnormal copies of the defective gene. Subjects that have one normal and one abnormal copy of the gene are symptom-free and are not known to be at increased risk for any disease.

Although the known number of missense, nonsense and frameshift mutations within CFTR exceeds 500 (50), a 3-base pair deletion in exon 10 is responsible for approximately $70 \%$ of the mutant alleles (3). This deletion results in the loss of a single amino acid, the phenylalanine at codon 508, and is thus designated as $\Delta \mathrm{F} 508$. The phenotype of patients bearing the $\Delta \mathrm{F} 508$ mutation varies considerably, but this mutation is often associated with severe disease.

The $\Delta \mathrm{F} 508$ mutation affects the structure, function and folding of the NBD1 (51). The alteration in the structure leads to defective processing of the $\Delta \mathrm{F} 508$-CFTR protein through the endoplasmic reticulum, resulting in a drastically reduced level of protein to be expressed on the plasma membrane of exocrine epithelia in patients carrying the $\Delta$ F508 mutation.

Most of the non- $\Delta \mathrm{F} 508$ mutations are relatively rare, ranging from $<1 \%$ to $10 \%$, and are not symmetrically distributed (Figure 1). In the first half of the gene almost $60 \%$ of the mutations are substitutions or deletions of amino acids, while in the second half nearly $80 \%$ are nonsense, frameshift or splice mutations. All the known CF mutations combined account for approximately $85 \%$ of all mutant chromosomes, and it is assumed that the remaining mutations may be located at the promotor or introns of the gene. In this review, we will focus on only a small number of mutations in specific functional domains of the protein that have been studied in more detail.

Besides the $\Delta \mathrm{F} 508$, both the G551D and G1349D missense mutations have been well studied as the cause of severe CF illness, characterized by severe respiratory disease, pancreatic insufficiency and high sweat $\mathrm{Cl}^{-}$ concentration (37). The G551D mutation occurs at the core of the Walker A binding motif for ATP in NBD1, a highly conserved residue among the ATP-binding cassette transporter family. The G1349D mutation is analogous to G551D, but is located in NBD2. Both mutations are thought to affect ATP binding in their respective NBDs.

On the other hand, the missense mutations A455E, P574H and G551S have been associated with less severe or mild pulmonary disease and/or less compromised CFTR function as a $\mathrm{Cl}^{-}$channel $(37,52,53)$. Smit et al. (53) explored the effect of natural and artificial mutations in the motifs of the NBDs thought to be important for ATP binding in CFTR. They showed that a severe mutation in one NBD was sufficient to critically reduce channel activity, but addition of a second severe mutation in the other NBD produced no additional defect.

Fulmer et al. (38) studied the A455E (associated with mild pulmonary disease) and G551D (associated with severe pulmonary disease) mutations concerning their effect on CFTR-ORCC regulatory interaction. They observed that the A455E-CFTR maintains about $67 \%$ of the chloride channel function while in the G551D-CFTR this function is reduced to $20 \%$. Moreover, only the A455E mutation in CFTR retained the ORCC regulating function. These findings suggest 
that the severity of pulmonary disease may be associated not only with the chloride function, but also (and perhaps mainly) with the regulatory role, rather than the channel function of CFTR.

Besides the mutations in NBDs, some mutations in TMDs have also been studied. In general, these mutations cause mild phenotypes in patients with CF (50). Several studies have examined the effects of TMD1 mutations on CFTR $\mathrm{Cl}^{-}$channel function $(54,55)$. Their results, taken together, indicate that the $\alpha$-helices 5 and 6 may form the central pore of the CFTR $\mathrm{Cl}^{-}$channel. Moreover, the results obtained by Piazza-Carrol et al. (24) suggest that alternative methionines can be used as translation initiation codons to translate the CFTR-mRNA into protein.

The effects of TMD2 mutations on CFTR function have not been examined and studies performed on the regulatory domain are confusing (56-58), further studies being necessary to achieve a better understanding of the function of the RD.

In conclusion, in addition to having a function in chloride transport, CFTR can modulate other conductances such as sodium channels (ENaCs) and chloride channels (ORCCs) probably by the mediation of ATP transport through the CFTR. The information obtained from the studies reviewed here shows the importance of the regulatory properties of CFTR at the cell plasma membrane level. The studies about the structure and function of CFTR are crucial for a better understanding of the defects involved in cystic fibrosis and for the development of alternative therapies for this complex human disease.

\section{Acknowledgments}

The authors are thankful to Dr. Doris Rosenthal for the suggestions and corrections of English grammar.

\section{References}

1. Riordan J M, Rommens J M, Kerem BS Alon N, Rozmahel R, Grzelvak Z, Zeilenski J, Lok S, Plavsic N \& Chou J L (1989). Identification of the cystic fibrosis gene: cloning and characterization of complementary DNA. Science, 245: 1066-1073.

2. Rommens J M, lannuzzi MC, Kerem B, Drumm $M L$, Melmer $G$, Dean $M$, Rozmahel R, Cole J L, Kennedy D, Hidaka N, Zsiga M, Buckwald M, Riordam J R, Tsui L \& Collins FS (1989). Identification of the cystic fibrosis gene: chromosome walking and jumping. Science, 245: 10591065.

3. Collins FS (1992). Cystic fibrosis: molecular biology and therapeutic implications. Science, 256: 774-779.

4. Boat TF, Welsh MJ \& Beaudet AL (1989). Cystic fibrosis. In: Scriver CR, Beaudet AL, Sly WS \& Valle D (Editors), The Metabolic Basis of Inherited Disease. McGrawHill, New York, 2649-2680.

5. Anderson MP, Rich DP, Gregory RJ, Smith AE \& Welsh MJ (1991). Generation of cAMP-activated chloride currents by expression of CFTR. Science, 251: 679682.
6. Bear CE, Li C, Kartner N, Bridges RJ, J ensen TJ , Ramjeesingh M \& Riordan J R (1992). Purification and functional reconstitution of the cystic fibrosis transmembrane conductance regulator (CFTR).Cell, 68: 809-818.

7. Hyde SC, Emsley P, Hartshorn MJ, Mimmack MM, Gileadi U, Pearce SR, Gallagher MP, Gill DR, Hubbard RE \& Higgins CF (1990). Structural model of ATP-binding proteins associated with cystic fibrosis, multidrug resistance and bacterial transport. Nature, 346: 362-365.

8. Crawford I, Maloney PC, Zeitlin PL, Guggino WB, Hyde SC, Turley H, Gatter KC, Harris A \& Higgins CF (1991). Immunocytochemical localization of the cystic fibrosis gene product CFTR. Proceedings of the National Academy of Sciences, USA, 88: 9262-9266.

9. Mulberg AE, Weyler RT, Altschuler SM \& Hyde TM (1998). Cystic fibrosis transmembrane conductance regulator expression in human hypothalamus. Neuroreport, 9: 141-144.

10. Reddy MM \& Quinton PM (1989). Altered electrical potential profile of human reabsorptive sweat duct cells in cystic fibrosis. American J ournal of Physiology, 257 (Cell Physiology, 26): C722-C726.

11. Bijman J \& Quinton P (1987). Permeability properties of cell membranes and tight junctions of normal and cystic fibrosis sweat ducts. Pflügers Archiv, 408: 505510.

12. Morales MM, Carroll TP, Morita T, Schwiebert EM, Devuyst O, Wilson PD, Lopes AG, Stanton BA, Dietz HC, Cutting GR \& Guggino WB (1996). Both the wild type and a functional isoform of CFTR are expressed in kidney. American J ournal of Physiology, 270 (Renal, Fluid and Electrolyte Physiology, 39): F1038-F1048.

13. Knowlton RG, Cohen-Haguenauer O, Van Cong N, Frezal J, Brown VA, Barker D, Braman J C, Schumm JW, Tsui LC, Buchwald M \& Donis-Keller H (1985). A polymorphic DNA marker linked to cystic fibrosis is located on chromosome 7. Nature, 318: 380-382.

14. Collins FS, Riordan J R \& Tsui L-C (1990). The cystic fibrosis gene: isolation and significance. Hospital Practice, 25: 47-57.

15. Deversen EV, Gow IR, Coadwell WJ , Mo- 
naco J J , Butcher GW \& Howard J C (1990). MHC class II region encoding proteins related to the multidrug resistance family of transmembrane transporters. Nature, 348: 738-741.

16. Moser J, Douar AM, Sarde CO, Kioschis P, Feil R, Moser H, Poutska AM, Mandel J L \& Aubourg P (1993). Putative X-linked adrenoleukodystropy gene shares unexpected homology with $A B C$ transporters. Nature, 361: 726-730.

17. Valle D \& Gartner J (1993). Penetrating the peroxisome. Nature, 361: 682-683.

18. Cliff WH, Schoumacher RA \& Frizzell RA (1992). cAMP-activated $\mathrm{Cl}^{-}$channels in CFTR-transfected cystic fibrosis pancreatic epithelial cells. American J ournal of Physiology, 262 (Cell Physiology, 5): C1154-C1160.

19. Bear CE, Duguay $F$, Naismith AL, Kartner N, Hanrahan J W \& Riordan J R (1991). $\mathrm{Cl}^{-}$ channel activity in Xenopus oocytes expressing the cystic fibrosis gene. J ournal of Biological Chemistry, 266: 1914219145.

20. Tilly BC, Winter MC, Ostedgaard LS, O'Riordan C, Smith AE \& Welsh MJ (1992). Cyclic AM P-dependent protein kinase activation of cystic fibrosis transmembrane conductance regulator chloride channels in planar lipid bilayers. J ournal of Biological Chemistry, 267: 94709473.

21. Sheppard DN \& Welsh MJ (1993). Inhibition of the cystic fibrosis transmembrane conductance regulator by ATP-sensitive potassium channel regulators. Annals of the New York Academy of Sciences, 707: 275-284.

22. Bear CE (1988). Phosphorylation-activated chloride channels in human skin fibroblasts. FEBS Letters, 237: 145-149.

23. Tabcharani J Á, Chang X-B, Riordan JR \& Hanrahan JW (1991). Phosphorylationregulated $\mathrm{Cl}^{-}$channel in $\mathrm{CHO}$ cells stably expressing the cystic fibrosis gene. Nature, 352: 628-631.

24. Piazza-Carrol T, Morales MM, Fulmer SB, Allen SS, Flotte TR, Cutting GR \& Guggino WB (1995). Alternate translation initiation codons can create functional forms of cystic fibrosis transmembrane conductance regulator. J ournal of Biological Chemistry, 270: 11941-11946.

25. Oblatt-Montal M, Reddy $\mathrm{GL}$, Iwamoto $\mathrm{T}$, Tomich J M \& Montal M (1994). Identification of an ion channel-forming motif in the primary structure of CFTR, the cystic fibrosis chloride channel. Proceedings of the National Academy of Sciences, USA, 91: 1495-1499.
26. McDonough S, Davidson N, Lester HA \& McCarty NA (1994). Novel pore-lining residues in CFTR that govern permeation and open-channel block. Neuron, 13: 623-634.

27. Schwiebert EM, Egan ME, Hwang T-H, Fulmer SB, Allen SS, Cutting GR \& Guggino WB (1995). CFTR regulates outwardly rectifying chloride channels through an autocrine mechanism involving ATP. Cell, 81: 1063-1073.

28. Reisin IL, Prat AG, Abrahan EH, Amara J F, Gregory RJ , Ausiello DA \& Cantielo HF (1994). The cystic fibrosis transmembrane conductance regulator is a dual ATP and chloride channel. J ournal of Biological Chemistry, 269: 20584-20591.

29. Abrahan EH, Okunieff $P$, Scala S, Vos P, Oosterveld MJ S, Chen AY \& Shrivastav B (1997). Cystic fibrosis transmembrane conductance regulator and adenosine triphosphate. Science, 275: 1324-1325.

30. Reddy MM, Quinton PM, Haws C, Wine J J, Grygorczyk R, Tabcharani J A, Hanrahan J W, Gunderson KL \& Kopito RR (1996). Failure of the cystic fibrosis transmembrane conductance regulator to conduct ATP. Science, 271: 1876-1879.

31. Grygorczyk R, Tabcharani J A \& Hanrahan J W (1996). CFTR channels expressed in $\mathrm{CHO}$ cells do not have detectable ATP conductance. J ournal of Membrane Biology, 151: 139-148.

32. Canhui L, Mohabir R \& Bear CE (1995). Purified cystic fibrosis transmembrane conductance regulator (CFTR) does not function as an ATP channel. J ournal of Biological Chemistry, 271: 11623-11626.

33. Grygorczyk R \& Hanrahan J W (1997). Cystic fibrosis transmembrane conductance regulator and adenosine triphosphate. Science, 275: 1325-1326.

34. Devidas S \& Guggino WB (1997). The cystic fibrosis transmembrane conductance regulator and ATP. Current Opinion in Cell Biology, 9: 547-552.

35. Schwiebert EM, M orales MM, Devidas S, Egan ME \& Guggino WB (1998). Chloride channel and chloride conductance regulator domains of CFTR, the cystic fibrosis transmembrane conductance regulator. Proceedings of the National Academy of Sciences, USA, 95: 2674-2679.

36. Sugita M, Yue $Y$ \& Foskett J K (1998). CFTR $\mathrm{Cl}^{-}$channel and CFTR-associated ATP channel: distinct pores regulated by common gates. EMBO J ournal, 17: 898908.

37. Drumm ML, Wilkinson DJ \& Smith WS (1992). Chloride conductance expressed by $\triangle \mathrm{F} 508$ and other mutant CFTRs in Xenopus oocytes. Science, 254: 1797-1799.
38. Fulmer SB, Schwibert EM, Morales $M$, Guggino WB \& Cutting GR (1995). Two cystic fibrosis transmembrane conductance regulator mutations have different effects on both pulmonary phenotype and regulation of outwardly rectifying chloride currents. Proceedings of the National Academy of Sciences, USA, 81: 1063-1073.

39. Mall M, Hipper A, Greger R \& Kunzelman K (1996). Wild type but not deltaF508 CFTR inhibits $\mathrm{Na}^{+}$conductance when coexpressed in Xenopus oocytes. FEBS Letters, 381: 47-52.

40. Stutts MJ, Canessa CM, Olsen J C, Hamrick M, Cohn J Á, Rossier BC \& Boucher RC (1995). CFTR as a CAMPdependent regulator of sodium channels. Science, 269: 847-850.

41. Ismailov II, Wayda A, J ovov MS, Beadiev BK, Fuller CM, Didman J R, Koetzel M \& Benos DJ (1996). Regulation of epithelial sodium channels by the cystic fibrosis transmembrane conductance regulator. J ournal of Biological Chemistry, 271: 4725-4732.

42. Ismailov II, Berdiev BK, Shlyonsky VG, Fuller CM, Prat AG, J ovov B, Cantiello HF, Ausiello DA \& Benos DJ (1997). Role of actin in regulation of epithelial sodium channels by CFTR. American J ournal of Physiology, 272 (Part 1): C1077-C1086.

43. Kunzelman K, Kiser G, Schreiber R \& Riordan J R (1997). Inhibition of epithelial sodium currents by intracellular domains of the cystic fibrosis transmembrane conductance regulator. FEBS Letters, 400: 341-344.

44. Briel M, Greger R \& Kunzelmann K (1998). $\mathrm{Cl}^{-}$transport by cystic fibrosis transmembrane conductance regulator (CFTR) contributes to the inhibition of epithelial $\mathrm{Na}^{+}$ channels (ENaCs) in Xenopus oocytes coexpressing CFTR and EnaC. J ournal of Physiology, 508 (Part 3): 825-836.

45. Wei LY, Hoffman MM \& Roepe PD (1997). Altered pHi regulation in 3T3/CFTR clones and their chemotherapeutic drugselected derivatives. American J ournal of Physiology, 272 (Part 1): C1642-C1653.

46. Wei LY, Stutts MJ , Hoffman MM \& Roepe PD (1995). Overexpression of the cystic fibrosis transmembrane conductance regulator in NIH 3T3 cells lowers membrane potential and intracellular $\mathrm{pH}$ and confers a multidrug resistance phenotype. Biophysical J ournal, 69: 883-895.

47. Trezise $A E$, Ratcliff $R$, Hawkins TE, Evans MJ , Freeman TC, Romano PR, Higgins CF $\&$ Colledge WH (1997). Co-ordinate regulation of the cystic fibrosis and multidrug resistance genes in cystic fibrosis knock- 
out mice. Human Molecular Genetics, 6: 527-537.

48. Trezise $A E$, Romano PR, Gill D, Hyde SC, Sepúlveda FV, Buchwald M \& Higgins CF (1992). The multidrug resistance and cystic fibrosis genes have complementary patterns of epithelial expression. EMBO J ournal, 11: 4291-4303.

49. Breuer W, Slotki IN, Ausiello DA \& Cabantchik IZ (1993). Induction of multidrug resistance downregulates the expression of CFTR in colon epithelial cells. American J ournal of Physiology, 265 (Cell Physiology, 34): C1711-C1715.

50. Schwiebert EM \& Guggino WB (1996). Abnormal chloride and sodium channel function in cystic fibrosis airway epithelia. In: Crystal RG \& West J B (Editors), The Lung: Scientific Foundations. 2nd edn. Lippincott-Raven Publishers, Philadelphia, 195.1-195.17.

51. Tomas PJ \& Pedersen PL (1993). Effects of the $\Delta \mathrm{F} 508$ mutation on the structure, function, and folding of the first nucleotide-binding domain of CFTR. J ournal of Bioenergetics and Biomembranes, 25: 11-19.

52. Cutting GR, Kasch LM, Rosestein BJ, Zielenski J, Tsui LC, Antonarakis SE \& Kazazian J r HH (1990). A cluster of cystic fibrosis mutations in the first nucleotidebinding fold of the cystic fibrosis conductance regulator protein. Nature, 346: 366369.

53. Smit LS, Wilkinson DJ, Mansoura MK, Collins FS \& Dawson DC (1993). Functional roles of the nucleotide-binding folds in the activation of the cystic fibrosis transmembrane conductance regulator. Proceedings of the National Academy of Sciences, USA, 90: 9963-9967.

54. Piazza-Carrol T, Mclntosh I, Egan ME, Zeitlin PL, Cutting GR \& Guggino WB (1994). Alternate translation initiation co- dons can create functional forms of cystic fibrosis transmembrane conductance regulator. J ournal of Biological Chemistry, 270: 11941-11946.

55. Sheppard DN, Rich DP, Ostedgaard LS, Gregory RJ , Smith AE \& Welsh MJ (1993). Mutations in CFTR associated with milddisease-form $\mathrm{Cl}^{-}$channels with altered pore properties. Nature, 362: 160-164.

56. Cheng SH, Rich DP, Marshall J, Gregory RJ , Welsh MJ \& Smith AE (1991). Phosphorylation of the R domain by CAMPdependent protein kinase regulates the CFTR chloride channel. Cell, 66: 10271036.

57. Chang X-B, Tabcharani J A, Hou Y-X J ensen TJ , Kartner N, Alon N, Hanrahan J W \& Riordan J R (1993). Protein kinase A (PKA) still activates CFTR chloride channels after mutagenesis of all 10 PKA consensus phosphorylation sites. J ournal of Biological Chemistry, 268: 11304-11311. 